\title{
In-flight emergencies: playing The Good Samaritan
}

\author{
B Shepherd ${ }^{1}$ D Macpherson ${ }^{2}$ C M B Edwards ${ }^{1}$
}

J R Soc Med 2006;99:628-631

\section{INTRODUCTION}

On a recent holiday, one of the authors was asked to lend medical assistance to a passenger on the flight out and another on the flight back. Anecdotally, it appears that other doctors are also being asked more often than previously. This led us to investigate the area more closely. About three quarters of in-flight emergencies are managed by cabin crew but in the remaining situations it is off-duty medical professionals who offer their services as Good Samaritans. ${ }^{1}$ This review article aims to identify and clarify issues surrounding doctors who act as Good Samaritans onboard commercial airline flights. This includes discussion points ranging from common clinical scenarios to the legal protection of an intervening doctor.

\section{PREVALENCE}

Various prevalence data sources exist but most have been derived from individual airlines. In 1999 British Airways reported about one in-flight medical incident per 11000 passengers. ${ }^{1}$ A 2000 UK Government report indicated that the number can be as high as one in 1400 passengers, though the estimate of medical events requiring professional intervention was thought to be about one per 14000 passengers. ${ }^{2}$ These data are an average of short- and longhaul flights; given the reduced time on the plane with the former and the decreased likelihood of passengers seeking help when they are closer to their destination, medical events are likely to be more prolific than this estimate on long haul flights. In addition, the numbers are likely to be subject to marked variations in reporting bias. In most cases, the problem is likely to escalate with the anticipated growth in air travel, with more elderly people and people with pre-existing disease taking to the air, and as airlines fight to reduce prices by increasing passenger numbers and reducing seat sizes. In contrast, the new A380 Airbus will initially fly at less than full capacity, and is reported to have more passenger space, which may mitigate against these factors. ${ }^{3}$ Longer baggage checking and security procedures induced by recent terrorist acts can increase mental stress and waiting times and may increase the number of incidents further.

'Diabeticare, Hillingdon Hospital, Pield Heath Road, Uxbridge, Middlesex, UB8 3NN, UK; ${ }^{2}$ School of Law, Kingston University, UK

Correspondence to: $\operatorname{Dr}$ C M B Edwards

\section{DO I HAVE TO INTERVENE?}

Under English law (unlike in some other jurisdictions, such as France), there is no legal duty to rescue a stranger, a clear distinction having been drawn between a responsibility 'not to make things worse', and the singular lack of any general responsibility 'to make things better', even if doing so would involve neither difficulty nor risk to the rescuer. Hence '.. . the bystander does not owe the drowning child . . . a duty to take steps to save him', ${ }^{4}$ and there is no legal obligation to treat a patient onboard a flight unless there is a pre-existing doctor-patient relationship. The issue of which country's law governs a flight is complex, and beyond the scope of this review. Only where there is a positive duty of care do issues of liability arise.

There are, however, moral and professional obligations for all doctors to act as Good Samaritans. The Hippocratic Oath states that a doctor has a special obligation to all fellow human beings and, in addition to the personal application of that broad principle, the General Medical Council enforce adherence to the 'Good Medical Practice' guidelines. In particular, paragraph 9 states that: 'in an emergency, wherever it may arise, you must offer anyone at risk the assistance you could reasonably be expected to provide. ${ }^{5} \mathrm{~A}$ doctor failing to volunteer his/her services in a medical emergency, without exceptional circumstances, risks losing their registration as a practising professional, although we are not aware of this happening in the UK.

Whether or not there is a legal duty of care, most doctors will, of course, wish to assist where they usefully can. By positively intervening the requisite doctor/patient relationship is created, the duty of care comes into existence, and the question that then arises is the extent of any potential liability - particularly in the tort of negligence - to which a doctor exposes themselves in so doing.

\section{WHAT CAN BE CONSIDERED NEGLIGENT?}

Under English law, the standard of care required by a doctor is that set out in the 'Bolam Test', ${ }^{6}$ which is whether in all the circumstances the person acted with the skill and competence ordinarily to be expected from a person undertaking his particular role and professing to have his particular skills - in other words, the skill expected of a reasonable professional. Lack of experience is not automatically a defence, for if one holds oneself out as a doctor, junior doctors must show the same degree of skill as 
those more experienced, or seek senior help if required. ${ }^{7}$ If a more experienced doctor than you is available you should obviously let them take the lead; negligence is certainly determined against the skill level professed. All procedures, of course, carry risk, and all activity involves the chance of error. Neither unfortunate outcomes nor errors, of themselves, constitute negligence. The important points are whether the procedure carried out was 'a practise accepted as proper by a responsible body of medical men skilled in that particular art', and whether an error made was one that might have been made by 'a reasonably competent professional professing to have the standard and type of skill the defendant held himself out as having, and acting with ordinary care. ${ }^{8}$ Generally, if other doctors can say they would have acted in a similar way in the same situation, then the requisite standard of care will have been met, though the courts will increasingly feel free to disregard medical opinion that is contested, controversial, or otherwise appears unreasonable. ${ }^{9}$ Cases of alleged negligence, however, will be considered in the context and circumstances in which they occur, so the quality of medical treatment required on board an aircraft in an emergency situation will be very different to that required in a controlled environment.

In general, therefore, the medical practitioner must recognize and inform both crew and passenger of the limits of their qualification and experience, and act within these limits. The principles of consent and documentation must be applied. Adherence to these principles should allow avoidance of the accusation of negligence.

\section{AM I INSURED?}

Indemnity is the security against damage, loss, or injury or a legal exemption from liability for damages. Under current British law, UK registered airlines operating out of the UK have no legal obligation to offer indemnity to Good Samaritans. It is at the discretion of the airline whether they offer this legal protection out of goodwill. British Airways, Virgin and other major carriers will indemnify a medical professional against legal liability, unless grossly negligent, that might arise from their assistance with an onboard medical emergency. In contrast, the US adopted legislation in 1998 in the form of the Aviation Medical Assistance Act, which includes a Good Samaritan provision. ${ }^{10}$ This protects passengers who step forward to offer medical assistance from liability unless they are guilty of gross negligence or wilful misconduct. This act dictates what happens on US registered aircraft only and the terms are irrespective of current airspace. Indemnity from the airline is only applicable if the airline requests your assistance, usually verbally via the tannoy. It does not apply if you spontaneously offer assistance, and you should therefore wait for a request to be issued. If assistance is requested directly by the passenger, as could occasionally happen, it is pertinent to inform airline staff of the situation and clarify that indemnity will be provided.

If an airline does not offer indemnity to the acting doctor, medical defence organizations will provide insurance in the event of any legal proceedings, unless the potential claimant is bringing the action in a court under American or Canadian jurisdiction. In reality, it is extremely rare for a passenger to take action against a Good Samaritan.

\section{DIVERSIONS}

Figures vary but Virgin Atlantic Airways give an average of 10 diversions a year from over 15000 flights. ${ }^{11}$ According to the Federal Aviation Administration in 2000, $13 \%$ of all in-flight medical incidents aboard domestic aircraft resulted in an emergency diversion. ${ }^{12}$ The most common clinical conditions resulting in diversion are cardiac, neurological and respiratory problems. ${ }^{12}$ Patient confidentiality prevents airlines from learning the outcome of the medical emergencies that caused the diversions, so experience is no guide in the decision-making process. Although theoretically patient consent could be requested and confidentiality retained, we know of no published data. Every professional should assess the patient and situation with care, and if it appears that the immediacy of on-ground medical attention is critical to the outcome then diversion should be advised. The most common cause of litigation is when a plane is not diverted on the basis of medical advice offered which subsequently results in an adverse outcome for the patient. Erring on the side of caution is advised: if the airline wishes to over-ride your opinion then liability resides with them. It is of some relief to learn that in one report there was $79 \%$ agreement between the in-flight medical diagnosis and the subsequent diagnosis made in hospital, and the passenger's condition improved in $60 \%$ of cases before arriving at hospital, suggesting the in-flight treatment was appropriate. ${ }^{12}$ As a caveat to this it should be noted that many of the patients may have improved without the doctor's input. Many airlines have direct links to ground-based medical teams, who will usually have training in aviation medicine. These aviation medicine staff will usually be accessed by the cockpit crew prior to making any suggestions to divert, although this latter decision ultimately rests with the captain.

\section{CABIN AIR QUALITY}

It is well recognized within the industry that the problem of requiring medical assistance onboard a flight will only escalate. An increasingly elderly population are more mobile and flying more miles. Passengers are coping with less luxurious surroundings with the boom of budget 
airlines. This impacts as reduced space with limited access to food and drink. In addition, airlines are obliged under anti-discrimination law to ensure that individuals with disabilities or chronic illnesses should be accommodated on flights wherever possible.

A worrying trend in terms of in-flight health is the practice by some airlines of optimizing passenger numbers at the expense of individual space allocations. Seat space is categorized by the dimensions pitch and width. Traditionally in economy class the pitch has been $32-34 \frac{1}{2}$ inches $(81-86 \mathrm{~cm})$ with the width $18-201 / 2$ inches $(46-51 \mathrm{~cm})$, though these measurements vary between airlines. However, the recent trend has been to pinch the inches. Airline seats vary in size, but currently most British Airways dimensions are $31 \times 17^{1 / 2}$ inches $(79 \times 43 \mathrm{~cm})$, Virgin seats are $32 \times 17.5^{1 / 2}$ inches $(81 \times 44 \mathrm{~cm})$, and Easyjet seats are $29 \times 17.5^{1 / 2}$ inches $(74 \times 44 \mathrm{~cm})$, according to their websites, and similar figures exist for all the budget airlines. ${ }^{13}$ There are two main implications of this: the first is the literal decrease in seat space, which can be detrimental in terms of reduced mobility and increasing the psychological stresses of flying; while the second relates to the effects of accommodating increasing numbers of people in a finite space, which reduces cabin air quality. These effects are likely to be exacerbated by the increasing size of passengers, who in most countries are still progressively getting both taller and more obese.

Cabin air quality encompasses cabin air pressure, oxygen levels, temperature, humidity and carbon dioxide levels, as well as noise and vibration. ${ }^{14}$ Although aircraft usually fly at more than 30000 feet $(9144 \mathrm{~m})$, the cabin pressure is standardized to an equivalent of 8000 feet $(2438 \mathrm{~m})$. At this cabin altitude the oxygen level circulating in arterial blood $\left(\mathrm{PaO}_{2}\right)$ drops from a sea level value of $103 \mathrm{mmHg}$ to about $69 \mathrm{mmHg}$, representing a decrease in oxygen blood saturation from $97 \%$ to $90 \%$. In addition, fresh air introduced into the cabin needs to be conditioned, resulting in a reduction in humidity to between $5 \%$ and $25 \%$. In a more cramped environment temperature and humidity levels become more difficult to control and oxygen partial pressures may fall; these factors certainly impinge on the comfort, if not the health, of passengers. Of note is that the new Airbus A380 has a standard cabin altitude of 6000 feet $(1829 \mathrm{~m})$, improving oxygen levels over those found in other aircraft, and passengers have reported feeling more comfortable at this pressure.

\section{CLINICAL SCENARIOS}

Clearly any clinical problem can present onboard an aircraft; however, there are some specifics that apply to flying. Fainting, vomiting and diarrhoea, dehydration and anxiety related problems are the most common scenarios encountered. ${ }^{15}$ It is usually only reassurance and advice that is offered by the intervening doctor, accompanied by common sense remedies.

Alcohol deserves a special mention, as it can cause many problems. It contributes to dehydration, especially in the context of reduced humidity; it can interact with medications; and, not least, it can cause intoxication with inappropriate behaviour. Insulin-dependent diabetics are particularly vulnerable whilst travelling due to altered meal times and regimes, with hypoglycaemic episodes occurring relatively frequently. The disruption of travel can also be a problem for any individual with a chronic illness that requires regular medication. Much publicized is the risk of deep venous thrombosis (DVT) and pulmonary embolus (PE), ${ }^{16}$ although the exact risks are unknown. It appears most likely that it is prolonged inactivity rather than air travel per se which is the major risk factor. Advice on prevention should be offered by the airline. However, it is rare for DVT or PE to manifest in-flight. Accidents are another main category of medical emergencies. Ranging from scalds to head injuries in turbulence, these are fortunately rare thanks to the diligence of cabin crew.

Changes in cabin air quality can contribute to or cause a passenger to be unwell. If an individual is compromised by a pathological process, either with cardiovascular, respiratory or blood disorders, then they may be unable to compensate and become unwell. Thus the relative hypoxia can worsen pre-existing ischaemic heart disease and heart failure, which are contra-indications to flying if known and unstable, ${ }^{17}$ as is known pulmonary disease. A pragmatic test of 'fitness to fly' is to see whether a patient can walk 50 yards $(46 \mathrm{~m})$ or climb a single flight of stairs without become severely dyspnoeic. ${ }^{17}$ Physical conditions associated with flying (immobility, cramped seating conditions, drowsiness, gastrointestinal expansion) can hinder the body's response to hypoxia, which is to increase the rate and volume of respiration. Gas expansion at altitude (38\% at 8000 feet) can also cause medical problems due to the effects on the enclosed gas-containing cavities of the body; the ears, sinuses, lungs and gastrointestinal tract, and in some people the eyes and teeth. The most common problem is the inability to equalize the pressures in the middle ear causing pain, particularly on descent. This is usually due to the common cold and catarrh blocking the Eustachian tube. Sinus pain is also a problem for similar reasons. Advice on swallowing or the Valsalva manoeuvre, decongestants and analgesia are the limits that a doctor has to offer. An infrequent but more serious implication of gas expansion at altitude is the effect on a pneumothorax. There is no documented increase in likelihood of a pneumothorax occurring in-flight. However, if one occurs at altitude there is an increased risk of tensioning, which is a genuine medical emergency requiring expert medical intervention, as was well publicized on one particular occasion. ${ }^{18}$ 
All airlines carry medical equipment, although the contents vary considerably. The most commonly used drugs are intravenous glucose, diazepam, sodium chloride, metoclopramide and salbutamol. ${ }^{11}$ Providers try to find a balance between possible medical requirements, storage space, training and cost effectiveness. In addition to the first aid basics, airlines usually have an automatic external defibrillator and drugs that are included in the Advanced Life Support protocols.

\section{CAN I CHARGE?}

Most airlines offer only token gestures as reward for acting as a Good Samaritan. A bottle of champagne or a free upgrade is usually the most one can hope for. There has been handful of cases where doctors have brought their own action in the small claims courts. A consultant psychiatrist who assisted with an on-board emergency in 1997 billed the airline for $£ 540$. It was felt that this case was only brought as a result of the lack of generosity of the airline in the first instance. When they refused to pay he took them to court, where he failed to win his case. ${ }^{19}$ Although the situation in the US is different, there have been no successful cases of doctors demanding payment in the UK. Charging for services rendered creates complications, not least a shift in expectations of the type and standard of care provided. In demanding a monetary reward doctors expose themselves further to litigation, as it is unlikely they would be covered by the airline's indemnity policy. Most policies refer specifically to Good Samaritans and not to doctors providing a paid service. A further complication would be whether the contract of payment is between the doctor and the passenger or the doctor and the airline. Most airlines have strict company policies that any payment is a matter between the doctor and the patient, and the fact that treatment occurred on their airline is irrelevant. It is unlikely that the situation will change in the near future and if the gift from the airline seems minimal, the only real comfort is the moral high ground.

\section{IF IT HAPPENS, WHAT DO I DO?}

So what should one do if the dreaded tannoy announcement is heard, or one is approached by a member of staff? If you are a medically qualified doctor still working and medically insured, then so long as you are sober, we would advise answering the call positively. Most patients and/or cabin staff will just need reassurance and a helping hand. If worried about the patient, you will find the cabin crew have access to many management and treatment options. If you feel the situation cannot be managed in the air you need to recommend to the pilot to divert, though usually it would be worth talking to a doctor on the ground first. Make sure you write everything down and if a mistake is not made you are very unlikely to run into problems. Likewise, you are unlikely to be rewarded for your actions . . . at least, not in this lifetime.

\section{CONCLUSION}

In a 1991 Federal Aviation Administration study, physician travellers were available in $85 \%$ of reported in-flight medical emergencies. ${ }^{20}$ Indeed, in 1997 one was not available when requested on Virgin Atlantic Airways flights only four times and in 1998 eight times. ${ }^{11}$ As such, it would seem likely that the airlines' reliance on doctors and the oft heard cry: 'If there is a doctor on board the aircraft, would they please make themselves known to the cabin crew' is likely to continue for the foreseeable future, though one can only hope that technological advances such as telemedicine will allow greater assistance from experts on the ground.

\section{REFERENCES}

1 Dowdall N. 'Is there a doctor on the aircraft?' Top 10 in-flight medical emergencies. BMJ 2000;321:1336-7

2 Select Committee on Science and Technology. Air Travel and Health: Fifth Report. London: House of Lords, 15 November 2000

3 www.airbus.com. Accessed 13 July 2006

4 Lord Nicholls. Stovin v Wise 19963 WLR 388

5 General Medical Council. Good Medical Practice. 3rd edn. London: GMC, 2001. Available at www.gmc-uk.org/standards (accessed 5 September 2005)

6 Bolam v Friern Hospital Management Committee 1957 WLR 583

7 Wilsher v Essex Area Health Authority 1987 QB 730

8 Whitehouse v Jordan 19861 ALLER 267

9 Bolitho v City \& Hackney Health Authority 1998 AC 232

10 Aviation Medical Assistance Act of 1998. Washington DC: National Archives and Records Administration, 1998

11 Goodwin T. In-flight medical emergencies: an overview. BMJ 2000;321:1338-41

12 DeJohn CA, Veronneau SJ, Wolbrink AM, et al. The evaluation of inflight medical care aboard selected US air carriers: 1996-1997. Washington DC: Federal Aviation Administration, Office of Aviation Medicine, 2000. DOT/FAA report AM-0013

13 www.airlinequality.com. Accessed 30th September 2005

14 Dehart RL. Health issues of air travel. Ann Rev Public Health 2003;24:133-51

15 Gendreau MA, DeJohn CA. Responding to medical events during commercial airline flights. N Engl J Med 2002;346:1067-73

16 Eklof B, Kistner RL, Masuda EM, Sonntag BV, Wong HP. Venous thromboembolism in association with prolonged air travel. Dermatol Surg 1996;22:637-41

17 Aerospace Medical Association, Medical Guidelines Taskforce. Medical Guidelines for Air Travel, 2nd edn. Aviat Space Environ Med 2003;74:A1-A19

18 Wallace WA, Wong T, O'Bichere A, Ellis BW. Managing in flight emergencies. BMJ 1995;311:374-6

19 Dyer C. Doctor demands payment for helping airline passenger. BMJ 1998;317:701

20 Hordinsky JR, George MH. Utilization of Emergency Kits by Air Carriers. Oklahoma City: Federal Aviation Administration, Civil Aeromedical Instuitute, 1991/ DOT/FAA report AM-91/2 